\title{
Intravenous Versus Subcutaneous Anti-TNF-Alpha Agents for Crohn's Disease: A Comparison of Effectiveness and Safety
}

\author{
Jinan Liu, PhD; Gosia Sylwestrzak, MA; Alexander P. Ruggieri, MD, MHS; and Andrea DeVries, PhD
}

\begin{abstract}
BACKGROUND: In recent years, there have been a number of pharmacological innovations for Crohn's disease (CD), a difficult-to-treat condition, including new treatment philosophies (e.g., top-down therapy) and new therapeutic options in terms of the agent and the route of administration. Three anti-tumor necrosis factor (anti-TNF-alpha) agents are available for use among CD patients in the United States: infliximab, an intravenous agent, and adalimumab and certolizumab pegol, 2 newer subcutaneous products. Infliximab is considered the "gold standard" because it has the longest clinical experience, and adalimumab and certolizumab pegol have each gained significant market share.
\end{abstract}

OBJECTIVE: To examine differences in effectiveness and safety between currently available intravenous and subcutaneous anti-TNF-alpha agents used to treat patients with CD.

METHODS: Data for this retrospective, administrative claims analysis were obtained from pharmacy and medical claims from major U.S. health plans geographically dispersed across 14 states during 2007-2011. Patients had at least 1 ICD-9-CM diagnosis for CD, 6 months pre-index eligibility, and initiated anti-TNF-alpha therapy on the index date. Patients in each cohort were propensity score matched on pre-index demographics, clinical characteristics, and baseline health care use. During the post-index period, age-sex adjusted incidence rate ratios (IRRs) of CD-related symptoms, infections, cancers, and hepatic-related conditions were compared using Cox (PH) models.

RESULTS: The matched cohorts included 515 patients in each group, with an average age of 39 years. Median follow-up was 17.5 months in the intravenous cohort and 17.7 months in the subcutaneous cohort. In terms of effectiveness outcomes, age-sex adjusted IRRs for the subcutaneous group, with the intravenous cohort as a reference, were as follows: 0.61 $(95 \% \mathrm{Cl}=0.32-1.18, P=0.14)$ for anal fissures; $0.97(95 \% \mathrm{Cl}=0.72-1.30$, $P=0.85)$ for abscess; $1.08(95 \% \mathrm{Cl}=0.79-1.04, P=0.64)$ for fistulas; 1.12 $(95 \% \mathrm{Cl}=0.83-1.54, P=0.45)$ for gastrointestinal hemorrhage; and 1.22 $(95 \% \mathrm{Cl}=0.93-1.59, P=0.14)$ for a combined measure of obstruction, occlusion, stenosis, and stricture of intestine. In terms of safety outcomes, age-sex adjusted IRRs for the subcutaneous group were as follows: 0.85 (95\% Cl=0.62-1.16, $P=0.30)$ for infections; $1.16(95 \% \mathrm{Cl}=0.71-1.89$, $P=0.55)$ for cancers; and $1.23(95 \% \mathrm{Cl}=0.79-1.92, P=0.35)$ for hepaticrelated conditions.

CONCLUSIONS: After adjusting for baseline characteristics, effectiveness and safety outcomes appear to be comparable between intravenous and subcutaneous anti-TNF-alpha agents in patients with CD. With similar outcomes, other considerations such as convenience of administration and patient preference may play a more prominent role in choice of agent. Health care providers and health payers should inform CD patients about the range of options available when selecting an anti-TNF-alpha agent.

J Manag Care Spec Pharm. 2015;21(7):559-66

Copyright $\odot 2015$, Academy of Managed Care Pharmacy. All rights reserved.

\section{What is already known about this subject}

The number of Americans with Crohn's disease (CD), a condition with no cure, is increasing. In the United States, direct costs associated with CD have reached $\$ 3.6$ billion annually.

Three anti-tumor necrosis factor (anti-TNF-alpha) agents (infliximab, adalimumab, and certolizumab pegol) were approved by the FDA for the treatment of CD in 1998, 2007, and 2008, respectively. In clinical trials, efficacy rates are similar among the agents, with $60 \%$ to $70 \%$ of patients showing a response, and all 3 agents are well tolerated.

Infliximab is administered intravenously (IV), requiring visits to a physician's office or infusion center; adalimumab and certolizumab are subcutaneous (SQ) injections, which allow patients to self-administer treatment.

\section{What this study adds}

This is the first study to compare routes of administration for antiTNF-alpha agents in a real-world setting, particularly in terms of specific CD-related symptoms and adverse events.

In this study, the IV and SQ anti-TNF-alpha agents demonstrated similar effectiveness and safety outcomes among patients with CD. Given comparable effectiveness and safety outcomes between IV and SQ anti-TNF-alpha agents, other factors, such as patient preference, should be considered when choosing CD therapy.

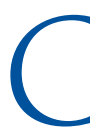

rohn's disease (CD), a condition involving chronic inflammation of the gastrointestinal tract, affects more than half a million Americans. ${ }^{1}$ CD has an estimated prevalence rate of 241 per 100,000 adults and, as a condition with no cure and low mortality, the number of Americans with $\mathrm{CD}$ is increasing. ${ }^{1}$ Overall, direct costs associated with $\mathrm{CD}$ have reached $\$ 3.6$ billion annually in the United States, with indirect costs, such as missed work, adding to the economic burden. $^{2}$

The exact cause of $C D$ is unknown, but treatments are available to help control symptoms and induce periods of remission. Step-therapy typically begins with aminosalicylates to control inflammation, progressing to corticosteroids or immunomodulators. ${ }^{3}$ If symptoms remain uncontrolled, biological therapies, such as anti-tumor necrosis factor (anti-TNF-alpha) agents, are indicated. ${ }^{3}$ The anti-TNF-alpha agents infliximab, adalimumab, and certolizumab pegol are approved by the U.S. Food 
and Drug Administration (FDA) for the treatment of moderateto-severe $\mathrm{CD}$ when other treatments have failed. Infliximab is administered as an intravenous (IV) infusion; adalimumab and certolizumab pegol are administered subcutaneously (SQ).-6 Whereas most patients must visit a physician's office or infusion center for their doses of infliximab, adalimumab and certolizumab may be administered by patients in their own homes, offering convenience and flexibility. ${ }^{7}$ Infliximab has been considered the "gold-standard" anti-TNF-alpha therapy for $C D$ primarily because it was first on the market, and there is a substantial body of research and experience available for the agent. In addition, the newer anti-TNF-alpha agents are becoming increasingly popular as treatment options.

Anti-TNF-alpha agents have demonstrated efficacy in inducing and maintaining remission in people with $\mathrm{CD}^{8-17}$ In its 2011 position statement based on a systematic literature review, the World Congress of Gastroenterology (WCOG) stated that clinical trials of anti-TNF-alpha agents for CD found generally similar response rates for infliximab (65\% for 5 milligrams per kilograms $[\mathrm{mg} / \mathrm{kg}]$ and $70 \%$ for $10 \mathrm{mg} / \mathrm{kg}$ ); adalimumab (60\%); and certolizumab (64\%), despite using different study populations. ${ }^{18-21}$ The reported potential adverse events include infection-most notably tuberculosis, sepsis, and candidiasis-with reports of malignancies and hepatic toxicities. ${ }^{16,22-26}$ In a study of certolizumab, with a 26-week follow-up, malignancies were reported in 4 patients-2 each in the 331 patients in the certolizumab group and in the 328 patients in the placebo group. ${ }^{16}$ A systematic review of all infliximab trials concluded that $0.5 \%$ of patients treated with infliximab developed malignancies compared with $0.06 \%$ in the placebo group. Since its approval in 1998, infliximab has accumulated millions of patient-years of data; however, the median followup of clinical studies is 1 year, which may be insufficient time for malignancies to develop. ${ }^{23}$ Drug-induced hepatic toxicities are rare in clinical studies, but because of cases reported during postmarketing surveillance, the FDA has issued warnings about the potential for serious liver injury related to use of any of the biologic agents. ${ }^{4-6,26}$

In clinical trials, the anti-TNF-alpha agents have individually demonstrated efficacy regardless of the route of administration. However, the clinical trials of anti-TNF-alpha agents, while numerous, have been limited to comparisons with placebo; no trials have directly compared established treatment (infliximab, IV group) and newer agents (certolizumab pegol and/or adalimumab, SQ group). Therefore, this study was designed to compare the effectiveness and safety outcomes of IV (infliximab) and SQ (certolizumab pegol and adalimumab) anti-TNF-alpha agents.

\section{Methods}

\section{Study Design and Setting}

This retrospective study included administrative claims for outpatient, inpatient, and pharmacological treatments from March 1, 2007, to July 31, 2011, for the population of patients with a $\mathrm{CD}$ diagnosis. We used data from the HealthCore Integrated Research Database, a repository of fully adjudicated medical and pharmacy claims data for approximately 50.3 million members of large commercial health plans geographically dispersed across 14 states: California, Georgia, Missouri, Colorado, Nevada, Indiana, Ohio, Kentucky, Virginia, Wisconsin, New York, Connecticut, New Hampshire, and Maine. The database represents claims information from one of the largest commercially insured population in the United States and includes health maintenance organizations, preferred provider organizations, and indemnity plans. To increase completeness of medical claims submissions, we allowed a 3-month runout period based on an internal analyses of the database that indicated nearly all (approximately 91\%) adjudicated medical claims become available within 3 months of the date when service was rendered.

Researchers only had access to a limited dataset; strict measures were taken to preserve anonymity and confidentiality and to ensure full compliance with the 1996 Health Insurance Portability and Accountability Act. This research was exempt from institutional review board approval because it involved a limited study database with masked patient identifiers.

\section{Patient Selection}

Patients were required to have at least 1 claim for infliximab, adalimumab, or certolizumab pegol from March 1, 2007, through July 31, 2011. The date of the first such claim was designated as the index date. Patients were divided into 2 mutually exclusive cohorts based on the initial treatment prescribed: the IV group for anti-TNF-alpha-naive patients who started on an intravenous anti-TNF-alpha (infliximab), and the SQ group for TNF-naive patients who started on a subcutaneous anti-TNF-alpha agent (adalimumab or certolizumab pegol).

All patients also had at least 1 claim with a CD diagnosis (International Classification of Diseases, Ninth Revision, Clinical Modification [ICD-9-CM] code 555.X) within 6 months before index date. All patients were required to have continuous medical and pharmacy health plan eligibility for at least 6 months prior to the index date, as well as a minimum of 1 month of follow-up (see Figure 1). The 6 months of pre-index eligibility was required to assess patients' baseline comorbidities and other health risks, as well as utilization patterns prior to initiating the anti-TNF alpha agents. A relatively short minimum eligibility post-index was established in order to prevent bias in case members of 1 cohort were more likely to leave the 


\section{FIGURE 1 Attrition Table for Intravenous and Subcutaneous Anti-TNF-Alpha} Cohorts Among Crohn's Disease Patients

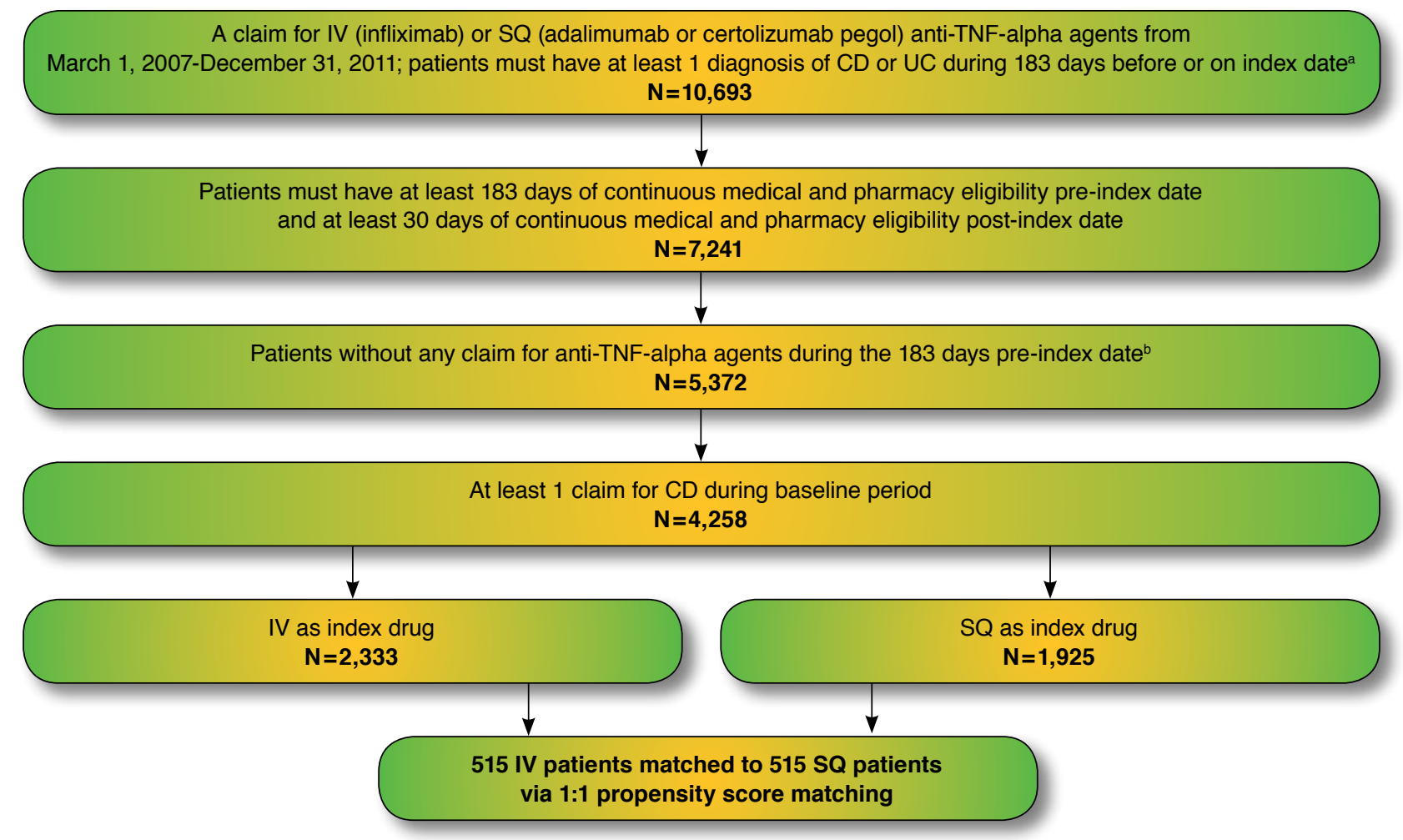

aThe date of the first such claim was defined as the index date.

${ }^{b}$ Anti-TNF-alpha agents included infliximab, adalimumab, certolizumab pegol, golimumab, etanercept, and efalizumab. $C D=$ Crohn's disease; $I V=$ intravenous; $S Q=$ subcutaneous; $T N F=$ tumor necrosis factor; $U C=$ ulcerative colitis.

insurance plan than the other (e.g., patients leaving the workforce and going on disability due to a worsening condition). Only patients aged 18 years or older were included in the analysis. Patients were excluded if they had any claim for antiTNF-alpha agents during the 6 months before the index date.

\section{Outcome Measures}

The primary outcomes involved the rates of effectiveness. Effectiveness was measured by the incidence of CD-specific complications and symptoms (i.e., anal fissures, abscess, fistula, gastrointestinal hemorrhage, and a combined measure of obstruction, occlusion, stenosis, or intestinal stricture). The secondary outcomes involved rates of safety events. Safety outcomes included the incidence of infections (e.g., candidiasis, sepsis, tuberculosis); cancers (e.g., solid tumor, lymphoma, hematologic malignancies); and hepatic-related conditions. Effectiveness outcomes as well as infection outcomes, except for anaphylaxis, were identified by requiring at least 1 claim containing corresponding ICD-9-CM diagnosis codes follow- ing therapy initiation. Anaphylaxis was identified by requiring at least 1 claim with corresponding ICD-9-CM diagnosis codes occurring within 2 days after anti-TNF-alpha use. Although infusion-related anaphylaxis will occur during or within 1 hour after infusion, a 2-day window was permitted to allow for potential service date discrepancies occurring with claims. With cancer outcomes, including solid cancer, lymphoma, and hematologic malignancies, patients were required to have at least 2 claims with corresponding ICD-9-CM diagnosis codes on 2 distinct service dates. See the Appendix for specific ICD9-CM diagnosis codes.

\section{Statistical Analysis}

An intent-to-treat protocol was followed for data analysis among TNF-naive users after assigning patients to the IV or SQ groups based on their index medication. Approximately $18.3 \%$ in the IV cohort had pharmacy fills for either certolizumab pegol or adalimumab after the index date; $5.8 \%$ in the SQ cohort had pharmacy fills for infliximab after the index date. Descriptive 
TABLE 1 Baseline Characteristics for Crohn's Disease Patients Treated with IV Versus SO Anti-TNF-Alpha Agents

\begin{tabular}{|c|c|c|c|}
\hline & $\begin{array}{c}\text { IV Anti- } \\
\text { TNF-Alpha } \\
(\mathrm{n}=515) \\
\text { n (\%) }\end{array}$ & $\begin{array}{c}\text { SQ Anti- } \\
\text { TNF-Alpha } \\
(\mathrm{n}=515) \\
\mathrm{n}(\%)\end{array}$ & $\begin{array}{c}P \\
\text { Value }\end{array}$ \\
\hline Age, years, mean (SD) & $39.3(14.4)$ & $39.2(14.2)$ & 0.93 \\
\hline Female & $287(55.7)$ & $272(52.8)$ & 0.35 \\
\hline \multicolumn{4}{|l|}{ CD-related symptoms } \\
\hline $\begin{array}{l}\text { Obstruction, occlusion, stenosis, } \\
\text { stricture of intestine }\end{array}$ & $80(15.5)$ & $87(16.9)$ & 0.55 \\
\hline Gastrointestinal hemorrhage & $75(14.6)$ & $92(17.9)$ & 0.15 \\
\hline Fistula & $61(11.8)$ & $55(10.7)$ & 0.55 \\
\hline Abscess & $56(10.9)$ & $45 \quad(8.7)$ & 0.25 \\
\hline Anal fissures & $15 \quad(2.9)$ & $23 \quad(4.5)$ & 0.19 \\
\hline Deyo-Charlson Index score, mean & $0.3 \quad(0.8)$ & $0.3 \quad(0.8)$ & 0.94 \\
\hline \multicolumn{4}{|l|}{ Baseline comorbidities } \\
\hline Ulcerative colitis & $87(16.9)$ & $98(19.0)$ & 0.37 \\
\hline Rheumatoid arthritis & $19 \quad(3.7)$ & $14 \quad(2.7)$ & 0.38 \\
\hline Ankylosing spondylitis & $11 \quad(2.1)$ & $8 \quad(1.6)$ & 0.49 \\
\hline Psoriatic arthritis & $1 \quad(0.2)$ & $5 \quad(1.0)$ & 0.22 \\
\hline \multicolumn{4}{|l|}{ Other comorbidities } \\
\hline Sinusitis & $48 \quad(9.3)$ & $39 \quad(7.6)$ & 0.31 \\
\hline Urinary tract infection & $41 \quad(8.0)$ & $35 \quad(6.8)$ & 0.48 \\
\hline Osteoarthritis & $26 \quad(5.0)$ & $22 \quad(4.3)$ & 0.55 \\
\hline Osteoporosis & $26 \quad(5.0)$ & $27 \quad(5.2)$ & 0.89 \\
\hline Upper respiratory infection & $23 \quad(4.5)$ & $28 \quad(5.4)$ & 0.47 \\
\hline Coronary heart disease & $20 \quad(3.9)$ & $24 \quad(4.7)$ & 0.54 \\
\hline Liver disease & $14 \quad(2.7)$ & $21 \quad(4.1)$ & 0.23 \\
\hline Chronic renal disease & $12 \quad(2.3)$ & $14 \quad(2.7)$ & 0.69 \\
\hline Cancer $^{\mathrm{a}}$ & $9 \quad(1.7)$ & $11 \quad(2.1)$ & 0.65 \\
\hline General infection & $6 \quad(1.2)$ & $9 \quad(1.7)$ & 0.44 \\
\hline Pneumonia & $6 \quad(1.2)$ & $9 \quad(1.7)$ & 0.44 \\
\hline Peptic ulcer disease & $5 \quad(1.0)$ & $2(0.4)$ & 0.45 \\
\hline Bronchitis & $4 \quad(0.8)$ & $5 \quad(1.0)$ & 1.00 \\
\hline Congestive heart failure & $3 \quad(0.6)$ & $9 \quad(1.7)$ & 0.08 \\
\hline Systemic lupus erythematosus & $3 \quad(0.6)$ & $1 \quad(0.2)$ & 0.62 \\
\hline Tuberculosis & $3 \quad(0.6)$ & $0 \quad(0.0)$ & 0.25 \\
\hline Pharyngitis & $1 \quad(0.2)$ & $4 \quad(0.8)$ & 0.37 \\
\hline \multicolumn{4}{|l|}{ Pre-index health care utilization } \\
\hline Physician office visit & $510(99.0)$ & $513(99.6)$ & 0.45 \\
\hline Outpatient visit & $502(97.5)$ & $500(97.1)$ & 0.70 \\
\hline Inpatient admission & $155(30.1)$ & $155(30.1)$ & 1.00 \\
\hline Emergency room visit & $122(23.7)$ & $115(22.3)$ & 0.60 \\
\hline \multicolumn{4}{|c|}{ Pre-index health care cost,$^{\text {b }}$ mean (SD) } \\
\hline Total cost & $\begin{array}{c}\$ 13,016 \\
(\$ 21,970)\end{array}$ & $\begin{array}{l}\$ 12,389 \\
(\$ 22,660)\end{array}$ & 0.18 \\
\hline CD-related cost & $\begin{array}{c}\$ 9,518 \\
(\$ 19,651)\end{array}$ & $\begin{array}{c}\$ 9,883 \\
(\$ 21,720) \\
\end{array}$ & 0.46 \\
\hline
\end{tabular}

\section{Treatments before anti-TNF-alpha agents}

\begin{tabular}{l|r|rr|c}
\hline Treatments before anti-TNF-alpha agents & $324(62.9)$ & $328(63.7)$ & 0.80 \\
\hline Aminosteroids & $247(48.0)$ & $273(53.0)$ & 0.11 \\
\hline Immune modifiers & $205(39.8)$ & $223(43.3)$ & 0.26 \\
\hline Antibiotics & $183(35.5)$ & $189(36.7)$ & 0.70 \\
\hline Surgery & $20(3.9)$ & 16 & $(3.1)$ & 0.50 \\
\hline
\end{tabular}

\footnotetext{
aTwo or more claims on distinct dates with a cancer diagnosis.
}

${ }^{\mathrm{b}}$ Cost was adjusted for inflation based on Medicare Care Services index (http:// data.bls.gov/cgi-bin/surveymost?cu) to 2012 US dollars; P values were based on nonparametric t-test.

$C D=$ Crohn's disease; $I V=$ intravenous; $S D=$ standard deviation; $S Q=$ subcutaneous; TNF $=$ tumor necrosis factor

statistics, including means (standard deviation [SD]) and frequencies were reported for continuous and categorical data, respectively. Propensity score to receive IV versus SQ anti-TNFalpha agents was created via logistic regression with demographics, comorbidities, and health care utilization (Table 1) as independent variables. A 1:1 propensity score matching with maximum acceptable distance of 0.001 was employed to make the groups more comparable. Cox proportional hazard model was used to compare age-sex adjusted incidence rates. Analyses were conducted using SAS version 9.2 (SAS Institute, Inc., Carey, NC). Statistical significance was set at 0.05.

\section{Results}

\section{Patient Characteristics}

After propensity score matching, the IV and SQ cohorts each contained 515 patients with a mean age of 39 years (Table 1). Median follow-up was 17.5 months in the IV group and 17.7 months in the SQ group. The majority of patients were female (55.7\% IV, 52.8\% SQ, P=0.35). At baseline, the most common comorbidity was ulcerative colitis (16.9\% IV, 19.0\% SQ, $P=0.37)$

The most common baseline CD-specific events were obstruction or intestinal stricture (15.5\% IV, 16.9\% SQ, $P=0.55)$ and gastrointestinal hemorrhage $(14.6 \% \mathrm{IV}, 17.9 \% \mathrm{SQ}$, $P=0.15)$. Few patients had general infection $(1.2 \% \mathrm{IV}, 1.7 \% \mathrm{SQ}$, $P=0.44)$; cancer $(1.7 \% \mathrm{IV}, 2.1 \% \mathrm{SQ}, P=0.65)$; or tuberculosis $(0.6 \% \mathrm{IV}, 0 \% \mathrm{SQ}, P=0.25)$ at baseline. Health care resource utilization was similar between the IV and SQ cohorts prior to the index visit (Table 1), suggesting similar overall health status of the 2 treatment groups. The majority of patients in both treatment groups used corticosteroids before beginning an anti-TNF-alpha regimen (62.9\% IV, 63.7\% SQ, $P=0.80$ ), with approximately half taking aminosalicylates $(48.0 \% \mathrm{IV}$, $53.0 \% \mathrm{SQ}, P=0.11$ ).

\section{Effectiveness Measures}

Measures of anti-TNF-alpha effectiveness in managing CD showed no between-group differences (Table 2). The combined measure of obstruction, occlusion, stenosis, or intestinal stricture was the most frequently reported CD-specific comorbidity in the IV (139.3 per 1,000 person-years) and SQ (173.0 per $1,000$ person-years $)$ groups $(P=0.14)$. Gastrointestinal hemorrhage (95.7 in IV vs. 109.3 in SQ; $P=0.45$ ); fistula (107.7 in IV vs. 117.7 in SQ; $P=0.64$ ); abscess (115.3 in IV vs. 115.1 in SQ; $P=0.85$ ); and anal fissures ( 27.4 in IV vs. $17.3 \%$ in SQ; $P=0.14$ ) were reported for smaller proportions of patients.

After adjusting for age and gender using the $\mathrm{Cox}(\mathrm{PH})$ model, the incidence rates were similar for both groups (Table 2). The incidence rate ratios (IRRs) for the SQ group compared with the IV group were 0.61 (95\% confidence interval $[\mathrm{CI}]=0.32-1.18, P=0.14)$ for anal fissures; 0.97 (95\% CI $=0.72$ - 
Intravenous Versus Subcutaneous Anti-TNF-Alpha Agents for Crohn's Disease: A Comparison of Effectiveness and Safety

TABLE 2 CD-Specific Symptoms Associated with IV Versus SO Anti-TNF-Alpha Agents Among CD Patients

\begin{tabular}{|c|c|c|c|c|c|c|}
\hline & \multicolumn{2}{|c|}{$\begin{array}{l}\text { IV Anti-TNF-Alpha } \\
\qquad(\mathrm{n}=515)\end{array}$} & \multicolumn{2}{|c|}{$\begin{array}{l}\text { SQ Anti-TNF-Alpha } \\
\qquad(\mathrm{n}=515)\end{array}$} & \multirow[b]{2}{*}{$\begin{array}{l}\text { Adjusted } \\
\text { IRR }^{\mathrm{b}}\end{array}$} & \multirow[b]{2}{*}{$P$ Value } \\
\hline & $\begin{array}{l}\text { Number of } \\
\text { Events }\end{array}$ & $\begin{array}{c}\text { Incidence } \\
\text { Rate }^{\mathrm{a}}\end{array}$ & $\begin{array}{l}\text { Number of } \\
\text { Events }\end{array}$ & $\begin{array}{l}\text { Incidence } \\
\text { Rate }^{\mathrm{a}}\end{array}$ & & \\
\hline Anal fissures & 24 & 27.4 & 15 & 17.3 & $0.61 \quad(0.32-1.18)$ & 0.14 \\
\hline Abscess & 91 & 115.3 & 87 & 115.1 & $0.97 \quad(0.72-1.30)$ & 0.85 \\
\hline Fistula & 84 & 107.7 & 88 & 117.7 & $1.08 \quad(0.79-1.04)$ & 0.64 \\
\hline Gastrointestinal hemorrhage & 76 & 95.7 & 84 & 109.3 & $1.12(0.83-1.54)$ & 0.45 \\
\hline Obstruction, occlusion, stenosis, stricture of intestine & 105 & 139.3 & 123 & 173.0 & $1.22 \quad(0.93-1.59)$ & 0.14 \\
\hline
\end{tabular}

1.30, $P=0.85)$ for abscess; $1.08(95 \% \mathrm{CI}=0.79-1.04, P=0.64)$ for fistulae; $1.12(95 \% \mathrm{CI}=0.83-1.54, P=0.45)$ for gastrointestinal hemorrhage; and $1.22(95 \% \mathrm{CI}=0.93-1.59, \mathrm{P}=0.14)$ for the combined measure of obstruction, occlusion, stenosis, and intestinal stricture.

In addition to the previously mentioned effectiveness measures, the concomitant treatments between the 2 cohorts was also examined. The concomitant treatments among these patients were very similar during the post-index date period (Table 3), including corticosteroids (64.7\% in the IV cohort vs. $61.7 \%$ in the SQ cohort, $P=0.33$ ); aminosalicylates ( $40.4 \%$ in the IV cohort vs. $43.7 \%$ in the SQ cohort, $P=0.28$ ); immune modifiers (40.0\% in the IV cohort vs. $39.6 \%$ in the SQ cohort, $P=0.90$ ); antibiotics ( $43.1 \%$ in the IV cohort vs. $46.4 \%$ in the SQ cohort, $P=0.29)$; and surgery $(13.8 \%$ in the IV cohort vs. $12.0 \%$ in the SQ cohort, $P=0.40$ ).

\section{Safety Outcomes}

Overall, rates of infection were 114.6 per 1,000 person-years in the IV group and 99.9 in the SQ group $(P=0.24)$, largely clustered in candidiasis (53.9 in IV group and 34.1 in SQ group, $P=0.08$ ); pneumonia (36.4 in IV group and 45.3 in SQ group, $P=0.34$ ); and sepsis (20.0 in IV group and 22.1 in SQ group, $P=0.98$; Table 4). Rates of tuberculosis were low for both groups (1.1 per 1,000 person-years in IV group and 3.4 per 1,000 person-year in SQ group, $P=0.35$ ).

For cancer metrics, the median time to event was 16.4 months, and the rate for any type of cancer was similar between the 2 groups (34.0 per 1,000 person-years in IV group, 42.2 in SQ group, $P=0.55$ ), including solid tumors (29.1 per 1,000 person-years in IV group vs. 40.8 in SQ group, $P=0.30$ ); lymphomas (3.3 per 1,000 person-years in IV group vs. 1.1 in SQ group, $P=0.34$ ); and hematologic cancers (1.1 per 1,000 person-years in IV group vs. 0 in SQ group, $P$ value not obtainable; Table 4). No between-group difference was seen for the incidence of hepatic-related diseases (40.6 per 1,000 personyears in IV group vs. 50.3 in SQ group, $P=0.41$ ).

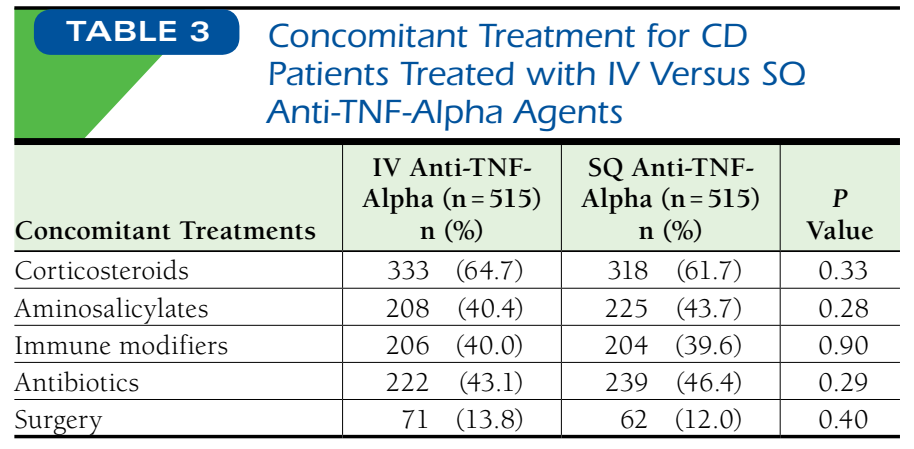

$C D=$ Crohn's disease; $I V=$ intravenous; $S Q=$ subcutaneous; $T N F=$ tumor necrosis factor.

After adjusting for age and gender using the Cox (PH) model, the incidence rates for safety metrics were similar for both groups (Table 4). The IRRs for the SQ group compared with the IV group were $0.85(95 \% \mathrm{CI}=0.62-1.16, P=0.30)$ for aggregated infection measure; 1.16 (95\% CI $=0.71-1.89$, $P=0.55)$ for all cancers; and $1.23(95 \% \mathrm{CI}=0.79-1.92, P=0.35)$ for hepatic-related disease.

\section{Discussion}

In this real-world analysis of the effectiveness and safety of anti-TNF-alpha agents in the treatment of CD, no statistically significant differences between agents delivered intravenously or subcutaneously were found.

Using CD-specific complications as a measure of effectiveness, no between-group differences were observed in the incidence of anal fissures, gastrointestinal hemorrhage, fistula, abscess, or a combined measure of obstruction, occlusion, stenosis, or intestinal stricture. The efficacy of anti-TNF-alpha agents in inducing and maintaining remission in patients with CD has been demonstrated in numerous clinical trials in comparisons with placebo. ${ }^{8-17}$ The current analysis, however, was unique not only in comparing all 3 anti-TNF-alpha agents approved for the treatment of $\mathrm{CD}$, but also in examining the 
Intravenous Versus Subcutaneous Anti-TNF-Alpha Agents for Crohn's Disease: A Comparison of Effectiveness and Safety

TABLE 4 Safety Outcomes Associated with IV Versus SO Anti-TNF-Alpha Agents Among CD Patients

\begin{tabular}{|c|c|c|c|c|c|c|}
\hline & \multicolumn{2}{|c|}{$\begin{array}{l}\text { IV Anti-TNF-Alpha } \\
(\mathrm{n}=515)\end{array}$} & \multicolumn{2}{|c|}{$\begin{array}{l}\text { SQ Anti-TNF-Apha } \\
(\mathrm{n}=515)\end{array}$} & \multirow[b]{2}{*}{ Adjusted IRR $^{\mathrm{b}}$} & \multirow[b]{2}{*}{$P$ Value } \\
\hline & Number of Events & Incidence Rate ${ }^{a}$ & Number of Events & Incidence Rate ${ }^{a}$ & & \\
\hline Infections & 92 & 114.6 & 78 & 99.9 & $0.85 \quad(0.62-1.16)$ & 0.30 \\
\hline Candidiasis & 46 & 53.9 & 29 & 34.1 & $0.66 \quad(0.41-1.04)$ & 0.08 \\
\hline Pneumonia & 32 & 36.4 & 38 & 45.3 & $1.25(0.78-2.00)$ & 0.34 \\
\hline Sepsis & 18 & 20.0 & 19 & 22.1 & $0.93 \quad(0.41-2.13)$ & 0.88 \\
\hline Multiple sclerosis & 2 & 2.2 & 1 & 1.1 & $0.50(0.04-5.56)$ & 0.57 \\
\hline Anaphylaxisc & 1 & 1.1 & 0 & 0 & NA & $\mathrm{NA}$ \\
\hline Tuberculosis & 1 & 1.1 & 3 & 3.4 & $2.94(0.31-25.00)$ & 0.35 \\
\hline Aspergillosis & 0 & 0 & 0 & 0 & NA & NA \\
\hline Coccidiomycosis & 0 & 0 & 0 & 0 & NA & NA \\
\hline Histoplasmosis & 0 & 0 & 0 & 0 & NA & NA \\
\hline Listeriosis & 0 & 0 & 0 & 0 & NA & NA \\
\hline Meningitis & 0 & 0 & 0 & 0 & NA & NA \\
\hline Pneumocystis & 0 & 0 & 0 & 0 & $\mathrm{NA}$ & NA \\
\hline Cancer $^{\mathrm{d}}$ & 29 & 34.0 & 34 & 42.2 & $1.16 \quad(0.71-1.89)$ & 0.55 \\
\hline Solid tumor & 25 & 29.1 & 33 & 40.8 & $1.32(0.78-2.22)$ & 0.30 \\
\hline Lymphoma & 3 & 3.3 & 1 & 1.1 & $0.33 \quad(0.03-3.23)$ & 0.34 \\
\hline Hematologic & 1 & 1.1 & 0 & 0 & NA & NA \\
\hline Hepatic-related diseases & 35 & 40.6 & 42 & 50.3 & $1.23(0.79-1.92)$ & 0.35 \\
\hline
\end{tabular}

ancidence rate per 1,000 person-years.

${ }^{b}$ Adjusted for age and gender (reference IV cohort).

'Up to 2 days after anti-TNF-alpha use.

'Two or more claims on distinct dates with diagnosis of cancer.

$C D=$ Crohn's disease; $I R R=$ incident rate ratio; $I V=$ intravenous; $N A=$ not applicable; $S Q=$ subcutaneous; $T N F=$ tumor necrosis factor.

effects between IV and SQ agents. Furthermore, the effectiveness measures used in the current study differed from previous clinical trials and other studies of CD therapies. Whereas previous studies used aggregate efficacy measures of complete or partial clinical response, each CD-specific complication was assessed separately. The claims analysis presented here also provides updated data on the use of anti-TNF-alpha agents in usual practice settings, filling gaps left by earlier research. For example, where a previous study noted the need for further research on the efficacy of the 2 SQ anti-TNF-alpha agents (adalimumab and certolizumab) in reducing the incidence of fistulizing $C D$, our analysis found no difference between these 2 SQ agents and the IV infliximab in occurrence of fistulae. ${ }^{27}$ These results indicate that in clinical practice, IV and SQ anti-TNF-alpha agents are similarly effective in controlling CD-specific comorbidities.

The safety outcomes assessed in this analysis were also similar for IV and SQ anti-TNF-alpha agents. Safety concerns associated with anti-TNF-alpha agents have been documented in the literature and include serious and opportunistic infections, tuberculosis, and hematologic malignancies. ${ }^{22-25}$ However, randomized clinical trials found rates of serious adverse events to be similar between biologic agents and placebo, and a study of adalimumab in clinical practice found rates of adverse events consistent with clinical trials. ${ }^{22,28-33}$ The results of this real-world analysis found little difference between the IV and SQ routes of administration in the incidence of sepsis, tuberculosis, malignancies, hepaticrelated diseases, or most other types of infection.

With little effectiveness and safety differences observed between anti-TNF-alpha agents when used in clinical practice, patient preferences play an important role in the choice of an anti-TNF-alpha agent. The WCOG statement recommends that providers discuss not only the efficacy and safety of anti-TNFalpha agents with their patients, but also the advantages and disadvantages of each delivery method when selecting a treatment for CD. ${ }^{18}$ IV treatment may be advantageous for patients who have difficulty complying with a self-injecting regimen or for patients who will feel a sense of safety when medical personnel are present. SQ administration may be advantageous for patients who desire flexibility and convenience because the medication can be administered at a time selected by the patient. Self-administration may also be preferred by patients who are active or in the workforce, since it eliminates the need to travel to a medical facility. ${ }^{34}$ Such a collaboration between the patient and provider is also supported by a recent survey of patients with $\mathrm{CD}$, which evaluated their preferences for antiTNF-alpha treatment delivery. ${ }^{34}$ In that survey, patients rated communication with their physicians as highly important when choosing $\mathrm{CD}$ treatment, and they indicated they were interested in learning about treatment options. However, fewer 
than half of the patients reported discussing anti-TNF-alpha treatment alternatives with their physicians. ${ }^{35}$ Given the lack of observed differences in effectiveness and safety, patient preferences should be considered when selecting an anti-TNF-alpha agent for the treatment of $\mathrm{CD}$, and patients should be educated regarding all available treatment options to make informed decisions with their physicians.

\section{Limitations}

There are several limitations that must be acknowledged. First, the outcome measures used in this study were obtained from ICD-9-CM codes on administrative claims. The diagnostic codes may have been entered incorrectly, miscoding may have occurred, or outcomes of interest may not have been captured. Second, as mentioned, the average follow-up was 17.5 months in the IV group and 17.7 months in the SQ group. While anti-TNFalpha clinical trials reporting the occurrence of malignancies typically had median follow-up periods of 1 to 2 years, these studies also acknowledged that the follow-up times were relatively short for agents that are taken over the long term. ${ }^{22-24}$ Some outcome measures, such as cancer, might take a longer time to develop and merit further research. Third, given that this study followed an "intent to treat" study design, treatment adherence was not measured; thus, it was not clear if patients switched to other CD therapy after initiation of the index anti-TNF-alpha treatment. Finally, demographic and clinical baseline differences were observed between cohorts. A propensity score matching approach was adopted to create balanced cohorts; however, unobserved baseline difference might have remained.

\section{Conclusions}

The findings from this study suggest that after adjusting for baseline characteristics, effectiveness and safety outcomes appear to be comparable between IV and SQ anti-TNF-alpha agents in patients with CD. With similar outcomes, other considerations, such as convenience of administration and patient preference, might play a more prominent role in choice of agent. Health care providers and health payers should inform patients with $\mathrm{CD}$ about the range of options available when selecting an anti-TNF-alpha agent.

\section{Authors}

JINAN LIU, PhD, is Associate Director, Merck \& Co., Kenilworth, New Jersey. GOSIA SYLWESTRZAK, MA, is Associate Director, and ANDREA DEVRIES, PhD, is Senior Director, HealthCore, Wilmington, Delaware. ALEXANDER P. RUGGIERI, MD, MHS, is Managing Medical Director, Anthem, Inc., Indianapolis, Indiana.

AUTHOR CORRESPONDENCE: Andrea Devries, PhD,

HealthCore, Inc., 123 Justison Ave., Ste. 200, Wilmington, DE 19801.

Tel.: 302.230.2145; Fax: 302.230.2020;

E-mail: adevries@healthcore.com.

\section{DISCLOSURES}

The authors received funding from Anthem, Inc., for the conduct of this study and have no financial or other conflicts of interest. Sylwestrzak and DeVries are employees of HealthCore, an independent subsidiary of Anthem, Inc., and a health outcome research organization. Lui was employed with Healthcore at the time of this study. Ruggieri is an employee of Anthem, Inc.

DeVries and Ruggieri developed the study concept, and Sylwestrzak, DeVries, and Liu designed this study. Liu and Sylwestrzak conducted the data analysis. All authors wrote and revised the manuscript.

\section{ACKNOWLEDGMENTS}

The authors thank Cheryl Jones, a medical writer at HealthCore for editorial assistance. The authors also want to recognize Curt Le, at Anthem, Inc., for his contribution to the definition of the study objectives and design.

\section{REFERENCES}

1. Kappelman MD, Moore KR, Allen JK, Cook SF. Recent trends in the prevalence of Crohn's disease and ulcerative colitis in a commercially insured U.S. population. Dig Dis Sci. 2013;58(2):519-25

2. Kappelman MD, Rifas-Shiman SL, Porter C, et al. Direct health costs of Crohn's disease and ulcerative colitis in United States children and adults. Gastroenterology. 2008;135(6):1907-13.

3. Bernstein CN, Fried M, Krabshuis JH, et al. World Gastroenterology Organization practice guidelines for the diagnosis and management of IBD in 2010. Inflamm Bowel Dis. 2010;16(1):112-24.

4. REMICADE (infliximab) lyophilized concentrate for injection, for intravenous use. Janssen Biotech. Revised January 2015. Available at: http:// www.remicade.com/shared/product/remicade/prescribing-information.pdf Accessed April 12, 2015.

5. HUMIRA (adalimumab) injection, for subcutaneous use. AbbVie. Revised December 2014. Available at: http://www.rxabbvie.com/pdf/humira.pdf. Accessed April 12, 2015.

6. CIMZIA (certolizumab pegol) for injection, for subcutaneous use. UCB, Inc. Revised October 2013. Available at: http://www.cimzia.com/assets/pdf/ Prescribing_Information.pdf. Accessed April 12, 2015.

7. Pache I, Rogler F, Felley C. TNF-alpha blockers in inflammatory bowel diseases: practical consensus recommendations and a user's guide. Swiss Med Whly. 2009;139(19-20):278-87.

8. Targan SR, Hanauer SB, van Deventer SJH, et al. A short-term study of chimeric monoclonal antibody cA2 to tumor necrosis factor $\alpha$ for Crohn's disease. N Engl J Med. 1997;337(15):1029-35.

9. Lémann M, Mary JY, Duclos B, et al. Infliximab plus azathioprine for steroid-dependent Crohn's disease patients: a randomized placebo-controlled trial. Gastroenterology. 2006;130(4):1054-61

10. Colombel JF, Sandborn WJ, Reinisch W, et al. Infliximab, azathioprine, or combination therapy for Crohn's disease. N Engl J Med. 2010;362(15):1383-95

11. Hanauer SB, Sandborn WJ, Rutgeerts P, et al. Human anti-tumor necrosis factor monoclonal antibody (adalimumab) in Crohn's disease: the CLASSIC-I trial. Gastroenterology. 2006;130(2):323-33.

12. Sandborn WJ, Rutgeerts P, Enns R, et al. Adalimumab induction therapy for Crohn's disease previously treated with infliximab: a randomized trial. Ann Intern Med. 2007;146(12):829-38.

13. Hibi T, Watanabe M, Camez A, et al. Efficacy and safety of adalimumab for the treatment of Japanese patients with moderately to severely active Crohn's disease: results from a randomized controlled trial. Am J Gastroenterol. 2008;103(Suppl 1s):S414-15.

14. Winter TA, Wright J, Ghosh S, Jahnsen J, Innes A, Round P. Intravenous CDP870, a PEGylated Fab' fragment of a humanized antitumor necrosis factor antibody, in patients with moderate-to-severe Crohn's disease: an exploratory study. Aliment Pharmacol Ther. 2004;20(11-12):1337-46. 
15. Schreiber S, Rutgeerts P, Fedorak RN, et al. A randomized, placebocontrolled trial of certolizumab pegol (CDP870) for treatment of Crohn's disease. Gastroenterology. 2005;129(3):807-18.

16. Sandborn WJ, Feagan BG, Stoinov S, et al. Certolizumab pegol for the treatment of Crohn's disease. N Engl J Med. 2007;357(3):228-38.

17. Sandborn WJ, Schreiber S, Feagan B, et al. Induction therapy with certolizumab pegol in patients with moderate to severe Crohn's disease: a placebo-controlled trial. Am J Gastroenterol. 2010;105(Suppl 1s):S419.

18. D'Haens GR, Panaccione R, Higgins PD, et al. The London Position Statement of the World Congress of Gastroenterology on Biological Therapy for IBD with the European Crohn's and Colitis Organization: when to start, when to stop, which drug to choose, and how to predict response? Am J Gastroenterol. 2011;106(2):199-212.

19. Hanauer SB, Feagan BG, Lichtenstein GR, et al. Maintenance infliximab for Crohn's disease: the ACCENT I randomised trial. Lancet. 2002:359(317):1541-49.

20. Colombel JF, Sandborn WK, Rutgeerts P, et al. Adalimumab for maintenance of clinical response and remission in patients with Crohn's disease: the CHARM trial. Gastroenterology. 2007;132(1):52-65.

21. Schreiber S, Khaliq-Kareemi M, Lawrance IC, et al. Maintenance therapy with certolizumab pegol for Crohn's disease. N Engl J Med. 2007;357(3):239-50.

22. Ford AC, Sandborn WJ, Khan KJ, Hanauer SB, Talley NJ, Moayyedi P. Efficacy of biological therapies in inflammatory bowel disease: systematic review and meta-analysis. Am J Gastroenterol. 2011;106(4):644-59.

23. Caviglia R, Boskoski I, Cicala M. Long-term treatment with infliximab in inflammatory bowel disease: safety and tolerability issues. Expert Opin Drug Saf. 2008;7(5):617-32

24. Colombel JF, Schwartz DA, Sandborn WJ, et al. Adalimumab for the treatment of fistulas in patients with Crohn's disease. Gut. 2009;58(7):940-48.
25. Marehbian J, Arrighi HM, Hass S, Tian H, Sandborn WJ. Adverse events associated with common therapy regimens for moderate-to-severe Crohn's disease. Am J Gastroenterol. 2009;104(10):2524-33.

26. Khokhar OS, Lewis JH. Hepatotoxicity of agents used in the management of inflammatory bowel disease. Dig Dis. 2010;28(3):508-18.

27. Peyrin-Biroulet L, Deltenre P, de Suray N, Branche J, Sandborn WJ, Colombel JF. Efficacy and safety of tumor necrosis factor antagonists in Crohn's disease: meta-analysis of placebo-controlled trials. Clin Gastroenterol Hepatol. 2008;6(6):644-53.

28. Shao LM, Chen MY, Cai JT. Meta-analysis: the efficacy and safety of certolizumab pegol in Crohn's disease. Aliment Pharmacol Ther. 2009;29(6):605-14.

29. Asgharpour A, Cheng J, Bickston SJ. Adalimumab treatment in Crohn's disease: an overview of long-term efficacy and safety in light of the EXTEND trial. Clin Exp Gastroenterol. 2013;6:153-60.

30. Kawalec P, Mikrut A, Wiśniewska N, Pilc A. Tumor necrosis factor- $\alpha$ (infliximab, adalimumab and certolizumab) in Crohn's disease: systematic review and meta-analysis. Arch Med Sci. 2013;9(5):765-79.

31. Huang ML, Ran ZH, Shen J, Li XB, Xu XT, Xiao SD. Efficacy and safety of adalimumab in Crohn's disease: meta-analysis of placebo-controlled trials. J Dig Dis. 2011;12(3):165-72.

32. Seminerio JL, Loftus EV Jr, Colombel JF, Thapa P, Sandborn WJ. Infliximab for Crohn's disease: the first 500 patients followed up through 2009. Dig Dis Sci. 2013;58(3):797-806.

33. Swoger JM, Loftus EV, Tremaine WJ, et al. Adalimumab for Crohn's disease in clinical practice at Mayo Clinic: the first 118 patients. Inflamm Bowel Dis. 2010;16(11):1912-21

34. Chilton F, Collett RA. Treatment choices, preferences and decision-making by patients with rheumatoid arthritis. Musculoskeletal Care. 2008;6(1):1-14.

35. Sylwestrzak G, Liu J, Stephenson JJ, Ruggieri AP, DeVries A. Including patient preferences when selecting anti-TNF therapeutic options. Am Health Drug Benefits. 2014;7(2):71-80. 
APPENDIX ICD-9-CM Codes for Effectiveness and Safety Metrics

\begin{tabular}{|c|c|}
\hline & ICD-9-CM Diagnosis Codes \\
\hline \multicolumn{2}{|l|}{ Effectiveness metrics } \\
\hline Abscess & $\begin{array}{l}\text { 5672x, 99859, 0400x, 566xx, 6822x, 5695x, 6825x, 5401x, 56961, 5695x, 5672x, 6829x, 5672x, } \\
99859,5672 x, 5650 x\end{array}$ \\
\hline Anal fissure & $5650 \mathrm{x}$ \\
\hline Fistula & $5651 x, 5374 x, 56981,566 x x, 9986 x, 6191 x, 5374 x$ \\
\hline Gastrointestinal hemorrhage & $5693 x, 5789 x, 5781 x, 5789 x, 7921 x$ \\
\hline Obstruction/occlusion/stenosis/stricture of intestine & $56081,5373 x, 5601 x, 56089,5601 x, 5609 x, 5692 x, 5373 x$ \\
\hline \multicolumn{2}{|l|}{ Safety metrics } \\
\hline \multicolumn{2}{|l|}{ Infections } \\
\hline Tuberculosis & $010 x-018 x$ \\
\hline Pneumonia & $480 x x-486 x x$ \\
\hline Meningitis & $320 x x-322 x x$ \\
\hline Sepsis & 99591, 99592, 78552, 7907x \\
\hline Histoplasmosis & $115 \mathrm{xx}$ \\
\hline Aspergillosis & $1173 x$ \\
\hline Listeria & $0270 x$ \\
\hline Pneumocystis carinii & $1363 x$ \\
\hline Coccidiomycosis & $1142 x$ \\
\hline Candidiasis & $112 \mathrm{xx}$ \\
\hline Anaphylaxis & $9950 x$ \\
\hline Multiple sclerosis & $340 \mathrm{xx}$ \\
\hline Cancer (malignant neoplasm) & $140 x-195 x, 196 x-199 x, 200 x x-208 x x, 230 x-234 x$ \\
\hline Solid tumors & $140 x-195 x$ \\
\hline Hematologic cancer & $203 x-208 x$ \\
\hline Lymphoma & $200 x-202 x$ \\
\hline Liver disease & $\begin{array}{l}07022,07023,07032,07033,07044,07054,4560,4561,45620,45621,5710,5712,5713,57140- \\
57149,5715,5716,5718,5719,5723,5728, V 427\end{array}$ \\
\hline
\end{tabular}

